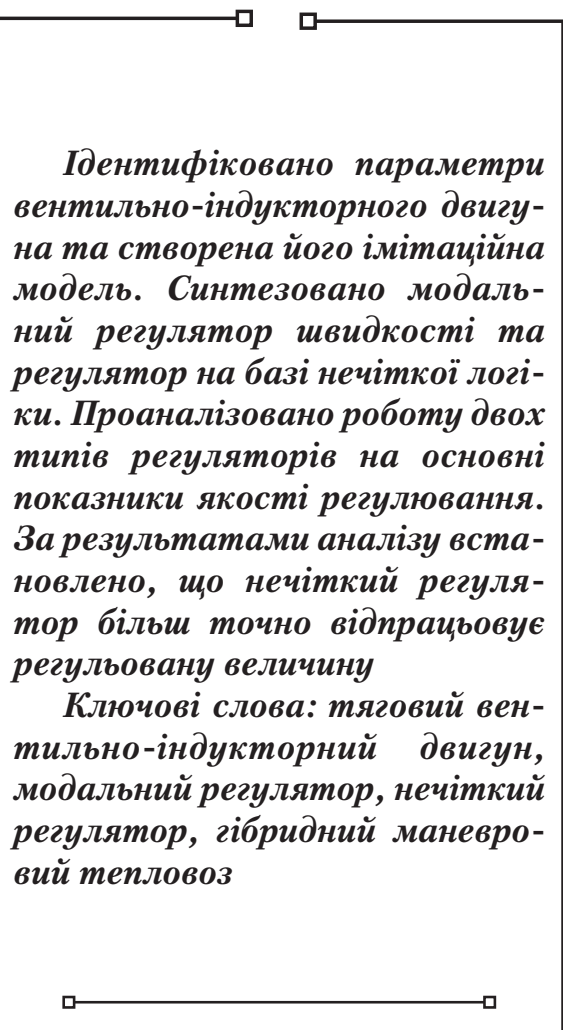

Идентифицированы параметры вентильно-индукторного двигателя и создана его имитационная модель. Синтезирован модальный регулятор скорости и регулятор на базе нечеткой логики. Проанализирована работа двух типов регуляторов на основные показатели качества регулирования. По результатам анализа установлено, что нечеткий регулятор более точно отрабатывает регулируемую величину

Ключевые слова: тяговый вентильно-индукторный двигатель, модальный регулятор, нечеткий регулятор, гибридный маневровый тепловоз

\section{QUALITY ASSESSMENT OF CONTROL OVER THE TRACTION VALVE-INDUCTOR DRIVE OF A HYBRID DIESEL LOCOMOTIVE}

S. Buriakovskyi

Doctor of Technical Sciences, Deputy Director Scientific Research and Design Institute "Molniya"*

E-mail: sergbyr@i.ua

M. B a b a i e v

Doctor of Technical Sciences, Professor, Head of Department**

E-mail:mmbxiit@gmail.com

B . Li u bar sk y i

Doctor of Technical Sciences, Professor Department of electrical transport and diesel locomotive*

E-mail: Iboris1911@ukr.net

Ar. Masli i

$\mathrm{PhD}$, Associate Professor**

E-mail: a.masliy@ukr.net

N. Karpenko

PhD, Associate Professor**

E-mail: kanape1909@gmail.com

D. Po m a z a n

Postgraduate student**

E-mail: danil.pomazan@ukr.net

An. Masli i

Engineer

LTD «Ukrtranssignal»

Lui Pastera str., 2, Kharkiv, Ukraine, 61075

E-mail: an_com@ukr.net

I. Denys

General director

PJSC «KARTEL.»

Dniprovske shose str, 84a, Kryvyi Rih, Ukraine, 50026

E-mail: div99@ukr.net

*National Technical University «Kharkiv Polytechnic Institute»

Kyrpychova str., 2, Kharkiv, Ukraine, 61002

**Department of electroenergy, electrical equipment and electromecanics

Ukrainian State University of Railway Transport

Feierbakha sq., 7, Kharkiv, Ukraine, 61050

\section{Introduction}

Statistical data reported in [1] reveal that $27 \%$ of all operations on Ukrainian railroads are performed by shunting locomotives. In addition, shunting locomotives are widely employed at industrial enterprises. Such operations imply the transportation of a small amount of cargo on short distances (for example, within a station, or an enterprise), which is why using powerful locomotives is impractical.
More than $90 \%$ of shunting locomotives in operation at present have exhausted their resource, thereby making a task on updating the fleet a pressing issue.

An analysis of the process to renovate the means of traction on world railroads shows [2, 3] that the polygon of railroads where the traction of diesel locomotives is applied, as well as the amount of transportation performed by diesel locomotives on railroads, occupy a leading place. Despite the fact that the countries of Western Europe and America have already (or 
almost) completed the process of introduction of advanced types of traction (which led to a certain decrease in the output of diesel locomotives in some countries), the need for diesel locomotives will remain stable in the world. In addition, many countries will require replacing and modernization of previously manufactured obsolete locomotives. Given this, the leading foreign companies that produce diesel locomotives, such as Brush Traction, Alstom, Toshiba, General Electric, intensify their work aimed at creating new designs of locomotives.

The result of the global trend for improving energy efficiency is the need to transfer to more environmentally-friendly and reliable types of shunting traction rolling stock. They represent of the most important controlling elements of railroad stations that ensure smooth operation. Given the above, creating hybrid assemblies for shunting traction with prospective control systems is one of the important scientific-technical tasks in railroad transportation.

\section{Literature review and problem statement}

Analysis [2] reveals that along with improving existing shunter locomotives by replacing unreliable elements, global companies have been working on creating the new types of them. Authors of [3] analyzed the trend that involves development of more reliable, energy efficient, and environmentally-friendly autonomous locomotives.

As noted in [4], the main requirements for shunting locomotives of the new generation are:

- maximal energy utilization in order to create traction power, minimize energy consumption for auxiliary needs and the cost of purchasing fuel and lubricants;

- to minimize labor costs over the life cycle, including the cost of maintenance and repairs of all types;

- advanced environmentally-friendly and ergonomic properties, which comply with the acting and would-be domestic and international standards.

As stated in [5], practical solution to the creation of a locomotive, which would meet the above-specified requirements, is to employ a combined (hybrid) power unit. This kind of unit, considered in [5], consists of the block of energy accumulators, for example, a traction battery, and a diesel generator set (DGS) of low power. A similar solution, investigated in [6], substantiated the possibility to reduce fuel consumption by not less than $40 \%$, since the larger part of shunting operations would be carried out using the power of the traction accumulator. This could ensure high environmental efficiency of the locomotive.

At present, there exists a large number of hybrid locomotives with an induction motor drive, which are analyzed in paper [6]. At the same time, increasingly used are the valve-inductor drives (VID), which are described in [7]. As stated in [8], such drives, by their traction parameters, are not inferior to DC motors and to the frequency-controlled drive; moreover, they possess significant advantages in their structural design.

Parameters of such an electromechanical energy transducer, specifically flux linkage and inductance, depend not only on the magnitude of current, but also on the position of the rotor. For example, inductance of a machine at the misaligned and aligned position of teeth of the rotor and the stator can vary by several times [9]. Such a change affects time constants of the engine, which are the input values when setting up the controllers. Control systems that are used in transportation [10] operate at fixed values of time constants, which is why applying them impairs the quality of dynamic modes of VID. Based on the analysis conducted, we can conclude that the nonlinear object of control, specifically the valve-inductor engine (VIE) in combination with a hybrid set, requires the application of custom systems based on fuzzy control algorithms.

\section{The aim and objectives of the study}

The aim of present work is to study dynamic modes of VID with controllers of different types, which would make it possible to choose the most efficient among them, estimated for quality (maximal overshoot, adjustment time, and the number of oscillations).

To accomplish the aim, the following tasks have been set:

- to identify parameters of the control object and to construct its simulation model;

- to synthesize the modal and the fuzzy-proportional-integrated-differential-(FPID) speed controllers and to analyze quality of their performance;

- to build a simulation model of the hybrid diesel locomotive with a valve-inductor drive and to study its dynamic modes;

- to fabricate a model sample and to test the operability of control system with the best indicators of controller quality.

\section{Construction of a mathematical model of the valve-inductor drive}

The substantiation of the transition to hybrid traction is given in [11]. Using the energy accumulators in the system makes it possible to give up the systems that control the diesel engine speed in favor of control systems over traction motors. In order to study performance of such a system, it is required to construct a mathematical model of the valve-inductor drive.

We have selected the VIE of brand DVI-165 to serve as the basis. A given engine is assembled in the configuration of $8 / 6$, its mathematical model represents the following system of differential equations [12, 13]:

$$
\begin{aligned}
& \int \frac{d i_{A}}{d t}=\frac{1}{\frac{\partial \Psi_{A}\left(i_{A}, \theta\right)}{\partial i_{A}}}\left(e_{A}-r_{A} i_{A}-\frac{\partial \Psi_{A}\left(i_{A}, \theta\right)}{\partial \theta} \omega\right), \\
& \frac{d i_{B}}{d t}=\frac{1}{\frac{\partial \Psi_{B}\left(i_{B}, \theta\right)}{\partial i_{B}}}\left(e_{B}-r_{B} i_{B}-\frac{\partial \Psi_{B}\left(i_{B}, \theta\right)}{\partial \theta} \omega\right), \\
& \left\{\begin{array}{l}
\frac{d i_{C}}{d t}=\frac{1}{\frac{\partial \Psi_{C}\left(i_{C}, \theta\right)}{\partial i_{C}}}\left(e_{C}-r_{C} i_{C}-\frac{\partial \Psi_{C}\left(i_{C}, \theta\right)}{\partial \theta} \omega\right) \\
\frac{d i_{D}}{d t}=\frac{1}{\frac{\partial \Psi_{D}\left(i_{D}, \theta\right)}{\partial i_{D}}}\left(e_{D}-r_{D} i_{D}-\frac{\partial \Psi_{D}\left(i_{D}, \theta\right)}{\partial \theta} \omega\right),
\end{array}\right. \\
& M_{d v}=f\left(i_{A}, i_{B}, i_{C}, i_{D}, \theta\right), \\
& \frac{d \omega}{d t}=\frac{M_{d v}-M_{s}}{J}, \\
& \frac{d \theta}{d t}=\omega,
\end{aligned}
$$


where $i_{A}, i_{B}, i_{C}, i_{D}$ are the currents of the stator's respective phases; $\psi_{A}, \psi_{B}, \psi_{C}, \psi_{D}$ are the flux linkages of the respective phases; $e_{A}, e_{B}, e_{C}, \mathrm{e}_{D}$ are the voltage of power sources; $\theta$ is the rotation angle of the rotor; $\omega$ is the angular velocity; $M_{d v}$ is the driving moment; $M_{s}$ is the moment of resistance; $J$ is the rotor's moment of inertia.

To identify the parameters of such engine, we applied the software complex FEMM, which calculates magnetic field using the method of finite elements. Figure 1 shows a distribution pattern of magnetic lines in VIE at switched phase A at the aligned and misaligned position. The results of calculation that we obtained were approximated by the method of Chebyshev polynomials. Fig. 2 shows the distribution surfaces of the phase flux linkage and electromagnetic moment.

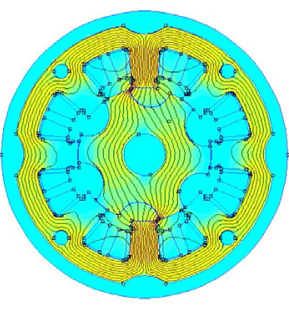

$a$

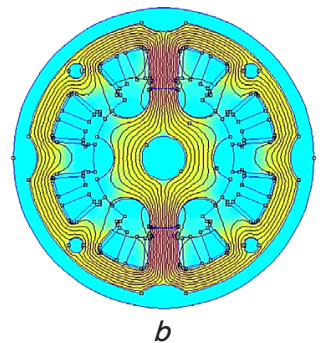

$b$

Fig. 1. Distribution of magnetic lines in VIE at switched phase A: $a-$ in the misaligned position; $b-$ in the aligned position
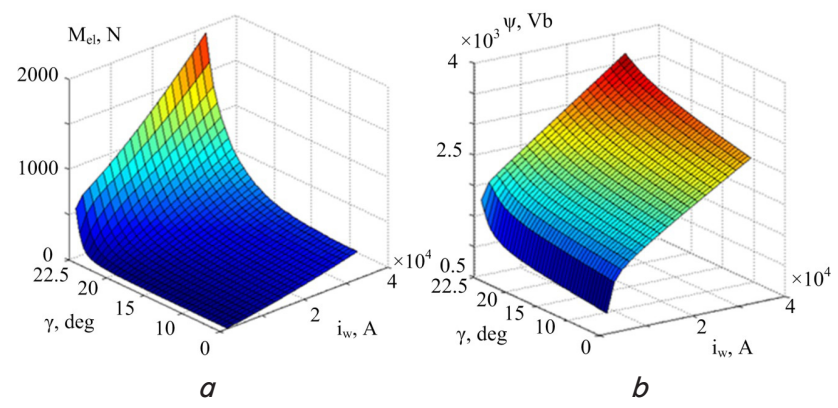

Fig. 2. Distribution surfaces: $a$ - electromagnetic moment depending on rotation angle of the rotor and

the magneto-driving force; $b$ - flux linkage depending on rotation angle of the rotor and the magneto-driving force

An integral part of the valve-inductor drive (VID) is an electronic switch (ES). ES is required for VID to connect phases of the motor to the power source depending on the signal of a rotor position sensor. Since the operation of VIE does not depend on the direction of current in the phase, then, in order to switch current, it typically employs a half-bridge (one-half-period) circuit [14]. In this case, each phase requires two switches and two reverse diodes. Thus, the number of power elements increases in proportion to the number of phases. In contrast to the circuit of switching an induction motor, the circuit for VIE switching has a significant advantage. It implies elimination of the occurrence of short circuit currents at simultaneous opening of the upper and lower power switches in vertical. Such switches are commonly field or IGB transistors. The occurrence of short circuit current is dangerous as the power source may fail, as well as transistors and devices of their control.

Using a system of differential equations (1), we developed a simulation model of the electromechanical energy transducer with ES. Fig. 3-7 show oscillograms of VIE direct start with a current limit at the level of $900 \mathrm{~A}$.

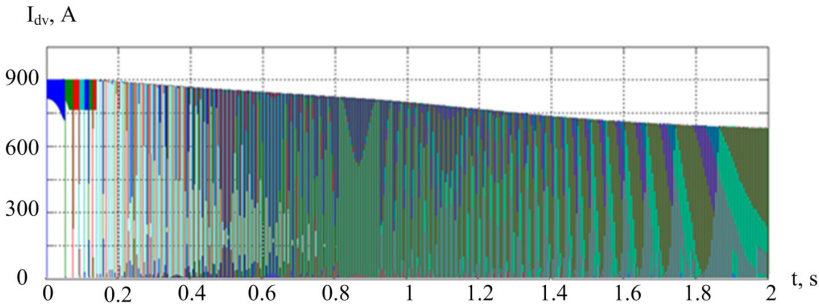

Fig. 3. Oscillogram of engine current at direct start

$I_{d v}, A$

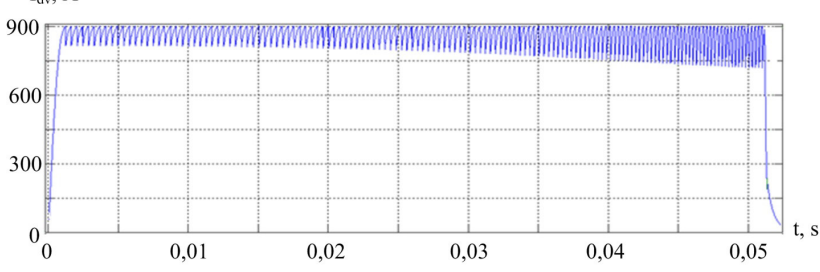

Fig. 4. Defragmentation of the oscillogram of engine's phase current $A$ at direct start

$\mathrm{M}_{\mathrm{dv}}, \mathrm{Nm}$

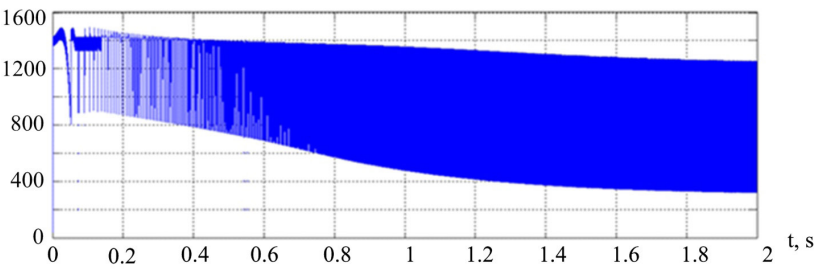

Fig. 5. Oscillogram of engine torque at direct start

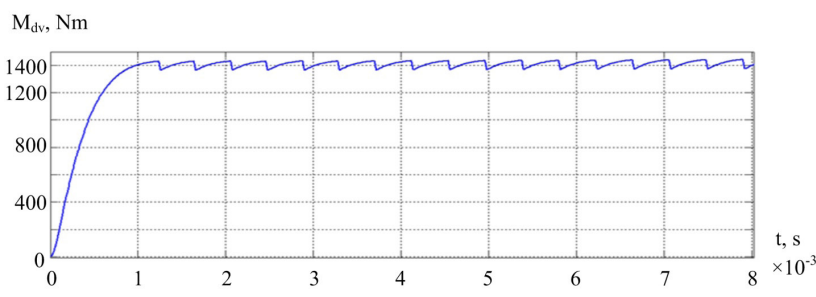

Fig. 6. Defragmentation of the oscillogram of engine torque at direct start

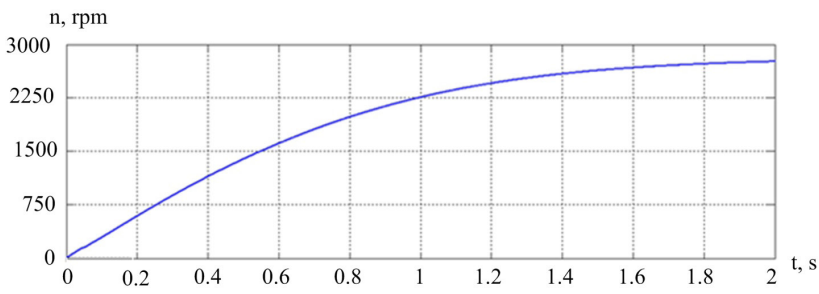

Fig. 7. Oscillogram of engine speed at direct start

The obtained results of modeling a direct start confirm that significant moment pulsations for this type of engine are inherent for a given type of engine. When current reaches a value of $670 \mathrm{~A}$ at the rated speed, they are in the range of $300-1,280 \mathrm{Nm}$.

\section{Synthesis of the modal and the FPID speed controller}

VID control system is a system of a subordinate regulation of coordinates with the possibility of applying various existing speed controllers $[9,10]$. Such speed controllers as 
P-, PI-, and PID are characterized by quality indicators that are not high enough to control the non-linear and complex systems [15]. Given the development of microprocessor technology, more widespread are control systems based on a modal regulator and fuzzy control. That is why further research is aimed at synthesizing these types of controllers.

A modal controller is the inertia-free regulator. It is included in the feedback link. At its input, algebraic summing of all feedbacks is performed for the state vector. A state of the system at any given time $t_{0}$ is a set of information about it whose availability suffices, along with a certain controlling influence, to predict the state of the system at any moment of time $t$.

In this case, in order to describe the system, it is appropriate to employ the apparatus of linear algebra [16].

Then $\mathrm{X}$ is nothing short of the vector-column of states of the system:

$$
\mathrm{X}=\left|\begin{array}{c}
X_{1}(t) \\
X_{2}(t) \\
X_{3}(t) \\
\cdots \cdots . . . \\
X_{n}(t)
\end{array}\right|
$$

$\mathrm{U}$ is the vector-column of control

$$
=\left|\begin{array}{l}
U_{1}(t) \\
U_{2}(t) \\
U_{3}(t) \\
\cdots \ldots . . \\
U_{r}(t)
\end{array}\right|
$$

$\mathrm{Y}$ is the vector-column of the system's outputs

$$
\mathrm{Y}=\left|\begin{array}{c}
Y_{1}(t) \\
Y_{2}(t) \\
Y_{3}(t) \\
\cdots \cdots . . \\
Y_{m}(t)
\end{array}\right| .
$$

Any linear stationary system can be described in the vector-matrix form by equations:

$$
\begin{aligned}
& \mathrm{X}=\mathrm{AX}+\mathrm{BU} ; \\
& \mathrm{Y}=\mathrm{CX}+\mathrm{DU},
\end{aligned}
$$

where

$$
\mathrm{A}=\left|\begin{array}{lll}
a_{11} \ldots & a_{1 n} \\
a_{n 1} \ldots & a_{n n}
\end{array}\right|
$$

is the square matrix of eigenvalues of dimensionality $n \times n$;

$$
\mathrm{A}=\left|\begin{array}{lll}
a_{11} \ldots & a_{1 r} \\
a_{n 1} \ldots & a_{n r}
\end{array}\right|
$$

is the rectangular matrix of control over dimensionality $n \times r$;

$$
\mathrm{A}=\left|\begin{array}{lll}
c_{11} \ldots & c_{1 n} \\
c_{m 1} \ldots & c_{m n}
\end{array}\right|
$$

is the rectangular matrix of coefficients of the output of dimensionality $m \times n$;

$$
\mathrm{A}=\left|\begin{array}{lll}
d_{11} \ldots & d_{1 r} \\
d_{m 1} \ldots & d_{m r}
\end{array}\right|
$$

is the matrix of control influence at the output of coordinate of dimensionality $m \times r$.

The system that is described by equations (6) is called fully controllable if, at a limited influence $U$, it can be transformed from any state $x_{0}\left(t_{0}\right)$ into any resulting state $x_{1}\left(t_{1}\right)$ at a change in time $t_{0} \leq t \leq t_{1}$. The condition for control is:

$$
\operatorname{Rang} P=n,
$$

where $n$ is the order of the system; $P$ is the matrix of controllability of dimensionality $n \times m$.

If condition (8) is met, it is possible to build a modal controller according to the structural circuit in Fig. 8.

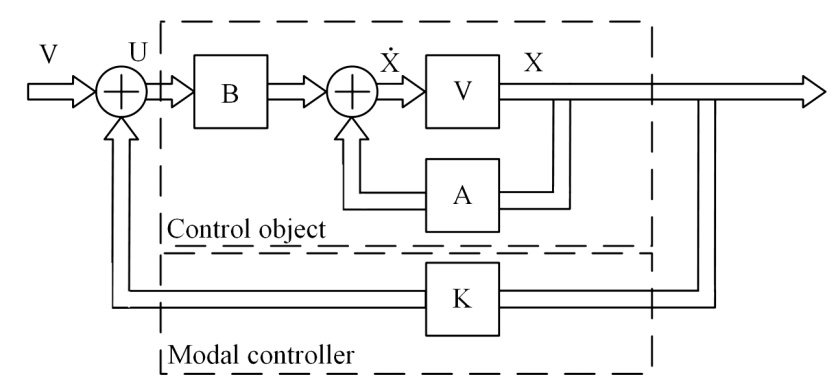

Fig. 8. Structural circuit of the closed multidimensional system with a modal controller

In this case, a closed control system will be described by the following equations:

$$
\left\{\begin{array}{l}
\dot{\mathrm{X}}=\mathrm{AX}+\mathrm{BU} \\
\mathrm{U}=\mathrm{V}-\mathrm{KX}
\end{array}\right.
$$

where $\mathrm{U}$ is the control matrix; $\mathrm{V}$ is the matrix of the task; $\mathrm{K}$ is the matrix-line of feedback, consisting of the coefficients of feedback for the vector of state X.

Based on the shown structural circuit, we built a simulation model of the operation of VID with a modal controller. Fig. 9-11 show oscillograms of current, moment of the engine, and the speed of the train.

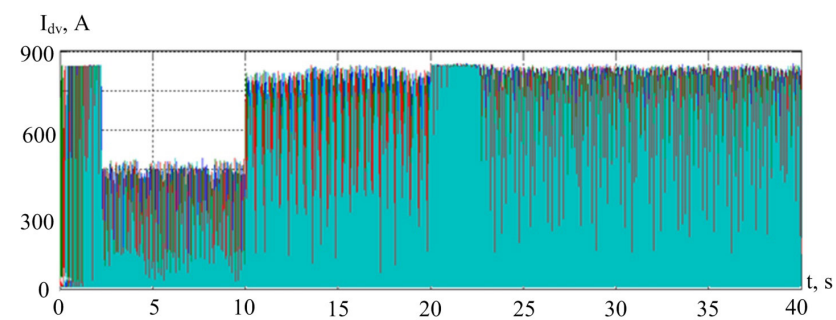

Fig. 9. Oscillogram of engine current when operating VID with a modal controller

The speed limit of the engine was set at 2,000 and $3,000 \mathrm{rpm}$. In a time of 10 seconds, additional load was applied to the engine, which corresponds to drawdown of speed.

Characteristics of controllers can be improved in some cases by using the methods of fuzzy logic $[9,17]$. 


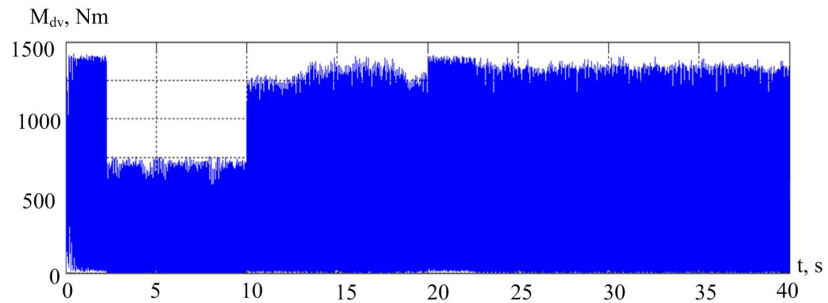

Fig. 10. Oscillogram of moment when operating VID with a modal controller

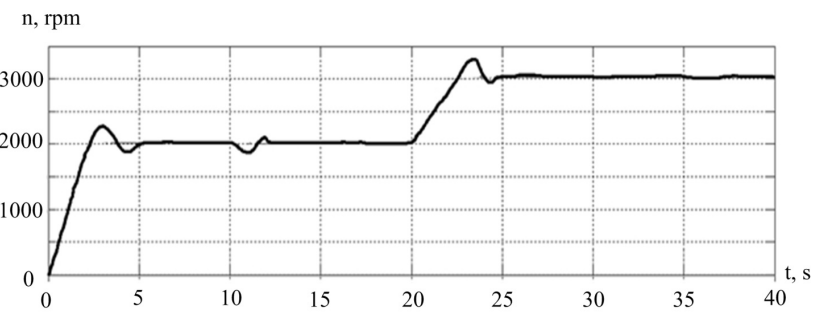

Fig. 11. Oscillogram of speed when operating VID with a modal controller

Underlying fuzzy logic is the theory of fuzzy sets, where the membership function of an element from the set is not binary, and may take any value in the range of $0-1$. Such logic makes it possible to build systems that are capable of processing inaccurate information. They make it possible to perform full range of logical operations over fuzzy sets: merging, intersection, denial, etc. [18], as shown in Fig. 12.

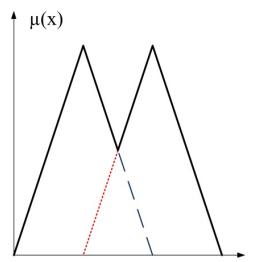

$a$

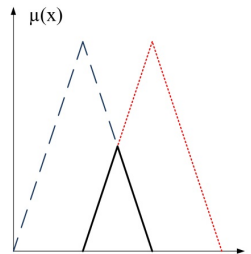

$b$

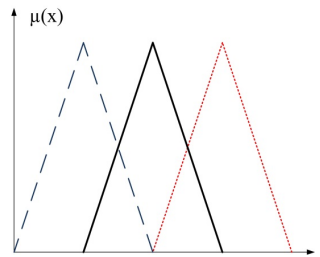

c
Fig. 12. Basic operations on fuzzy sets: $a$ - merging; $b$ - intersection, $c-$ denial

A general structure of systems with fuzzy control is shown in Fig. 13.

In the example we use as input variable a difference between the assigned and actual values of controlled parameter, in our case, the speed of engine rotation. This difference, together with its derivative for time, is transferred to the very system of fuzzy control as two input variables. At the same time, a variable for the correction of the controlled parameter is obtained based on the original variable of the system of fuzzy control, by using a unit of calculation of controlling variables.
In order to construct a fuzzy-controller, we applied the procedure reported in paper [18]. The structure of fuzzy PID-controller for DVI-165 is shown in Fig. 14.

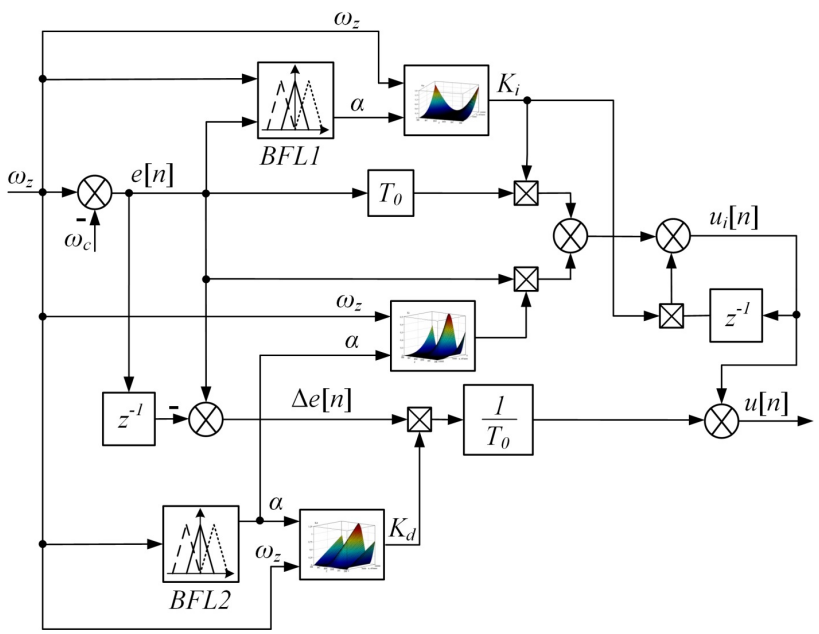

Fig. 14. Structural circuit of fuzzy PID-controller

Based on the shown structural circuit, we built a simulation model of the operation of VID with a modal controller. Fig. 15-17 show oscillograms of current, engine moment, and speed.

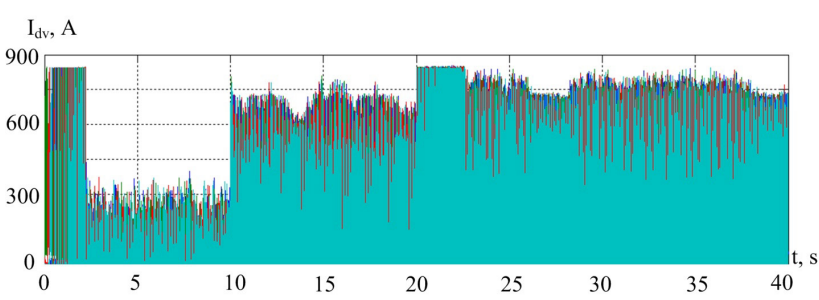

Fig. 15. Oscillogram of engine current when operating VID with a fuzzy controller

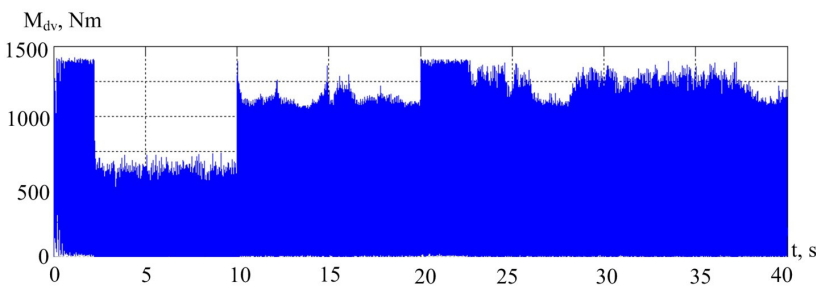

Fig. 16. Oscillogram of moment when operating VID with a fuzzy controller

Upon analyzing the oscillograms of operation of the drive with a modal and a FPID controller, we obtained basic performance quality indicators summarized in Table 1.

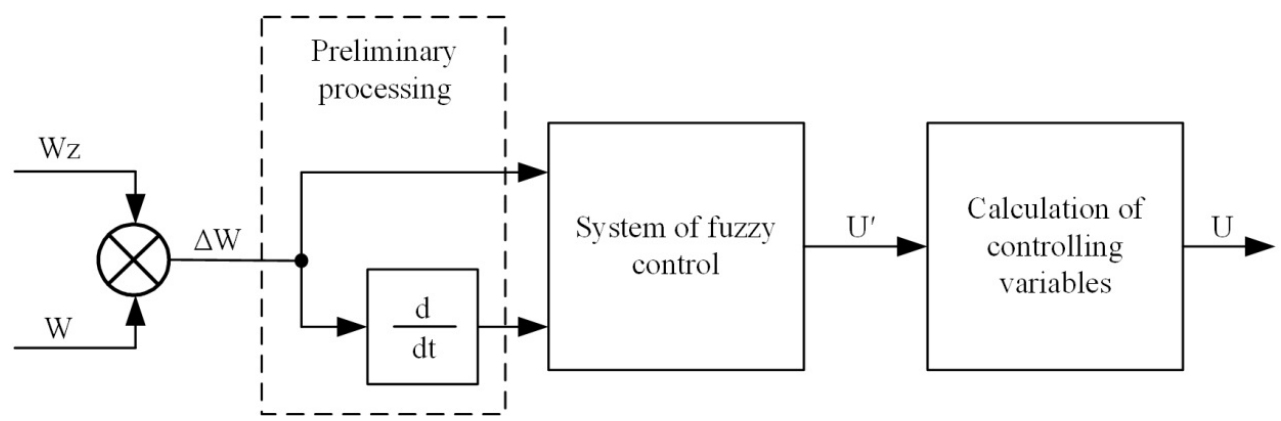

Fig. 13. Generalized functional circuit of fuzzy control 


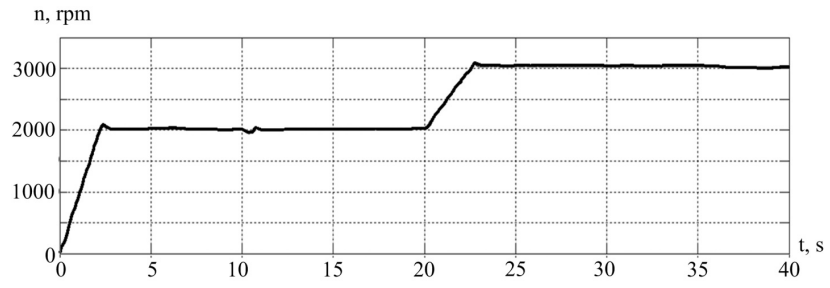

Fig. 17. Oscillogram of speed when operating VID with a fuzzy controller

Table 1

Basic indicators of the quality of control processes

\begin{tabular}{|l|c|c|}
\hline \multicolumn{1}{|c|}{ Quality indicator } & Modal controller & Fuzzy controller \\
\hline Maximum overshoot, $\sigma_{\max }, \%$ & 12.27 & 3.75 \\
\hline Control time, $t_{p}, \mathrm{~s}$ & 5.08 & 3.01 \\
\hline Number of oscillations, $N_{p}$ & 2 & 1 \\
\hline
\end{tabular}

A transition process for speed with a modal controller has an overshoot, which is almost completely absent when using fuzzy logic. We have achieved a reduction in the control time up to 2.07 seconds, confirming the appropriateness of employing such a control system on traction rolling stock.

\section{Analysis of the operation of hybrid VID of shunting locomotive with a fuzzy speed control}

The principle of modernizing a shunting locomotive was considered in more detail in paper [11] where it was proposed to install a diesel generator set with a synchronous generator of low power that recharges accumulator and capacitor batteries. The batteries power, through static converters, traction valve-inductor engines. A design circuit of the modernized locomotive is shown in Fig. 18.

The system of transformation of thermal energy into electric energy acts as batteries charger and does not exert any significant influence on the operation of traction electric drive. That is why when building a simulation model, the system diesel-generator - energy accumulator was replaced with a constant voltage power source.

An analysis of the operation of traction electric drive of the hybrid locomotive with a fuzzy speed controller was performed at a section of the railroad from Kharkiv to Merefa (Ukraine) with an actual profile shown in Fig. 19, speed limit, and a train weight of 723 tons. Substantiation of the choice of optimal regime for passing the section is given in $[19,20]$.

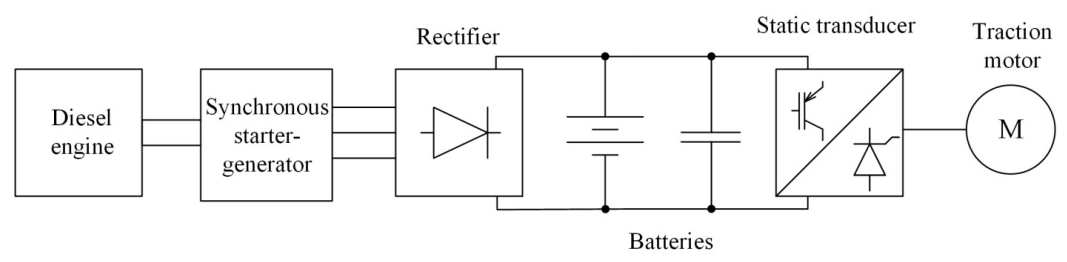

Fig. 18. Design circuit of the modernized locomotive

Fig. 20-22 show oscillograms of current, moment of traction VIE, and the speed of train motion.

The charts derived confirm high accuracy and speed performance of the synthesized FPID-controller and the expediency of application of such a system for hybrid rolling stock.

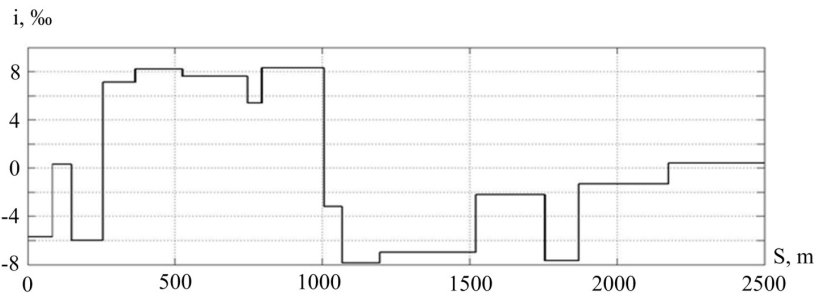

Fig. 19. Profile of section from Kharkiv to Merefa

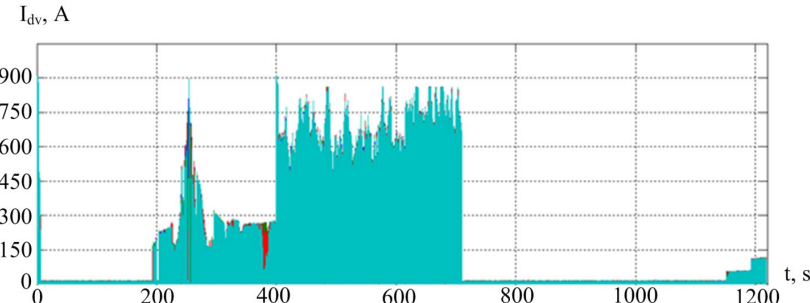

Fig. 20. Oscillogram of current of traction VIE during train motion

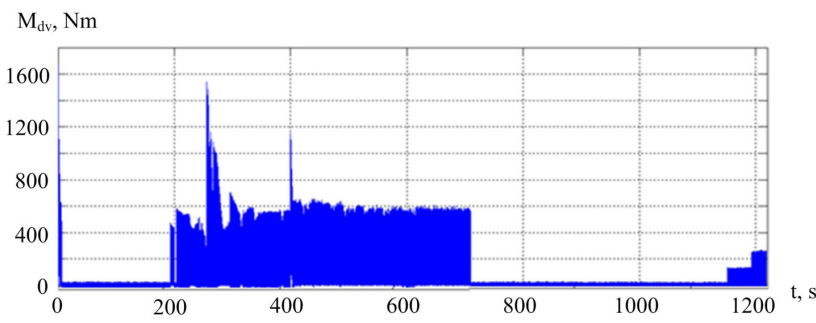

Fig. 21. Oscillogram of torque of traction VIE during train motion

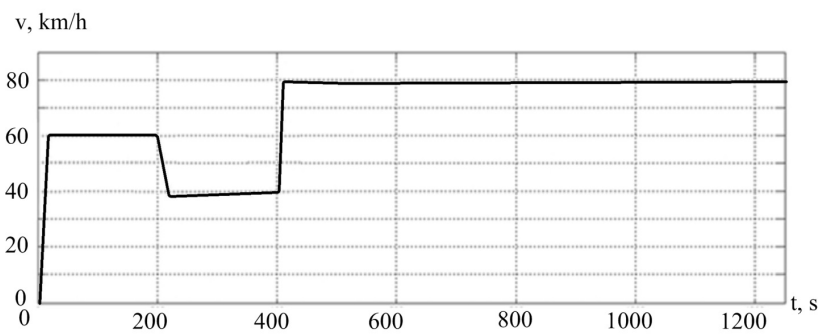

Fig. 22. Oscillogram of train motion speed

8. Confirmation of feasibility of
the traction valve-inductor drive with
a synthesized control system

To confirm the feasibility of VID with a FPID speed controller, we fabricated a model sample whose physical appearance is shown in Fig. 23.

In this case, the wheelset is attached by racks to the base via two supporting bearings. A gear is mounted onto the engine shaft, and the wheelset holds a cog wheel with 16 and 51 teeth, respectively. Transmission number of the gear unit is 3.2. The engine is rigidly fixed to the base. Power wires and control wires are separated and shielded to protect against interference and disturbance. We used a lever of the mechanical brake as a load. Power source voltage $U d=100 \mathrm{~V}$ during tests was 
maintained at a constant level with a PWM frequency of $20 \mathrm{kHz}$, at current limit at the level of $3 \mathrm{~A}$. To facilitate work with a model sample, connection to the LCD display is enabled. with the possibility to visualize information, which is especially important at the stage of adjustment.
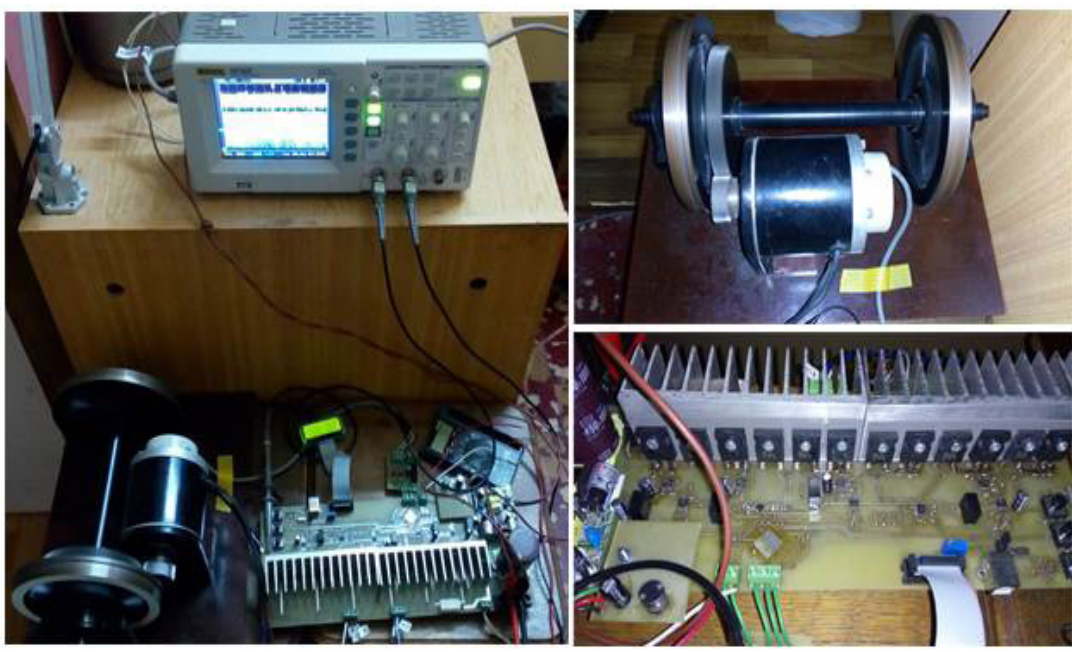

Fig. 23. Model sample of VID with a FPID-controller

Testing of VID was carried out employing a control system based on fuzzy logic. The purpose of experiments was to analyze performance of the drive at different speeds of machine rotation, stabilization of speed, ensuring smooth acceleration of engine (and wheelset, accordingly), acquiring oscillograms of basic coordinates of the transition process. By using a computer, we fully controlled the drive: range, smoothness and direction of speed regulation, the choice of algorithm for smooth start and ensuring the required starting effort.

When the engine reached the preset speed of 2,000 rpm at a time moment of 13 seconds, additional load was applied in a stepwise fashion, which is matched with a drawdown of speed as shown in Fig. 24.
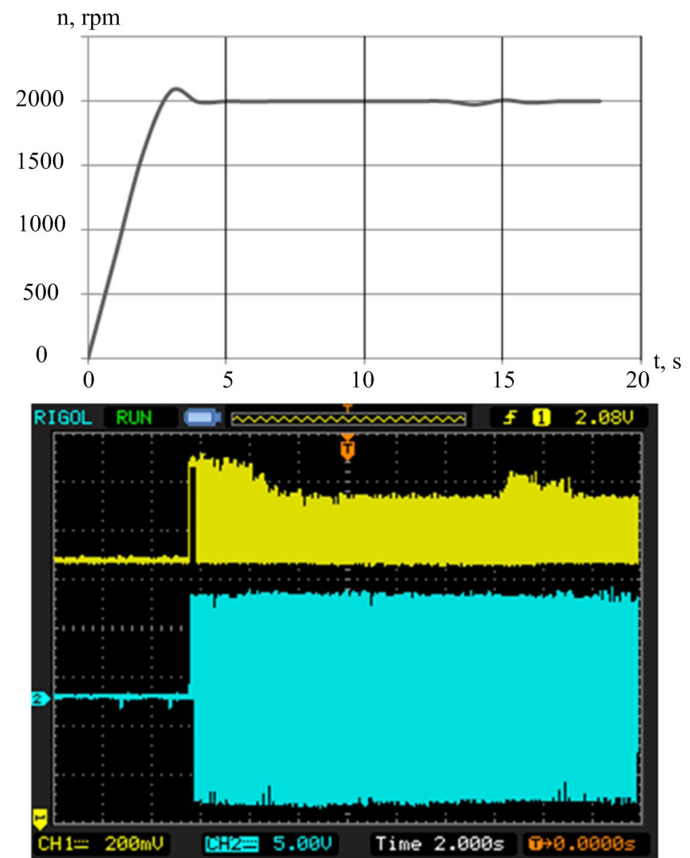

Fig. 24. Oscillograms of the operation of VID with a FPID controller
During work of the drive, we investigated emergency mode of the engine using fuzzy logic (disabling one of the phases was purposefully enabled in the transducer). At the same time, it worked continuously, which confirms the adequacy of procedure for the synthesis of a FPID-controller proven by physical simulation on the model sample of VID.

\section{Discussion of results of studying the operation modes of control systems over the traction valve-inductor drive}

The results of the simulation of direct start of VIE show that when maintaining a phase current of the engine at the level of 900 A, electromagnetic moment amounted to $1,400 \mathrm{Nm}$. One can also conclude that significant moment pulsations are inherent for a given type of engine is. It is recommended to build a control system that would ensure the optimal mode of ES operation both in terms of minimizing the moment pulsations and maximizing the performance efficiency.

The designed simulation model of VIE does not account for the mutual influence of adjacent phases, yielding an error of up to $7 \%$, however, it makes it possible to take into consideration its nonlinearities. This necessitates the construction of non-standard speed controllers, specifically the modal and the FPID controller.

The study of the two synthesized control systems allowed us to establish that the best quality indicators of speed control were demonstrated by a fuzzy controller, which, accordingly, proves the feasibility of its application.

When investigating the work of a hybrid locomotive using a simulation model as an example, we studied an actual profile of the railroad (Fig. 14). The model constructed does not make it possible to take into consideration resistance of the train along the curved sections, condition of the track, impact of the environment, etc. Further consideration of these components will make it possible to determine as the percentage of the main resistance the degree of influence of the specified factors on the accuracy of simulation. This would allow us to argue about the expediency of the complication of the model.

There are no drawdowns in speed when changing the load (Fig. 17), which confirms the high accuracy and performance speed of the synthesized FPID- controller; charts in Fig. 19 demonstrate feasibility of such a system.

The studies conducted in continuation of work reported in [11] allow us to devise algorithms of control over a traction drive based on VIE. This makes it possible to employ the microprocessor equipment, to construct new means for electric motor protection, as well as to select the required operation mode of both the drive and a hybrid locomotive. The research we conducted implies, in the future, studying the operation of control systems not only under traction regime, but also under regenerative mode.

\section{Conclusions}

1. We identified parameters of the valve-inductor engine for a hybrid shunting locomotive in the form of dependences 
of phase flux linkages and their derivatives for currents and rotation angle of the engine's rotor, as well its electromagnetic moment. A special feature of identification is the application of a finite element method for the calculation of magnetic field, and the Chebyshev polynomials for the approximation of obtained discrete experimental data.

2. Control systems based on a modal controller and fuzzy logic were synthesized. It is established that the modal controller has the following quality indicators: maximal overshoot $-12.27 \%$, re-adjustment time $-5.08 \mathrm{~s}$, number of oscillations - 2. For the FPID-controller, the quality indicators are: $3.75 \%, 3.01 \mathrm{~s}$, and 1, respectively.
Thus, upon analyzing the quality of their operation, it was found that the best indicators were demonstrated by the FPID-controller.

3 . The adequacy of procedure for the synthesis of FPIDcontroller was proven by physical simulation using a model sample of VID as an example at the rated load and under emergency modes.

4. The research results have shown that the construction of drives based on VIE makes it possible to improve quality indicators of the control system. This would ensure the process of control over train motion along a section of the track with the assigned profile and motion schedule.

\section{References}

1. Efimenko Yu. I., Kovalev V. I., Loginov S. I. Zheleznye dorogi. Obshchiy kurs: uchebnik / Yu. I. Efimenko (Ed.). Moscow: UMC ZHDT, 2014. 503 p.

2. Koseki T. Technical trends of railway traction in the world // The 2010 International Power Electronics Conference ECCE ASIA. 2010. doi: 10.1109/ipec.2010.5544539

3. Drofenik U., Canales F. European trends and technologies in traction // 2014 International Power Electronics Conference (IPEC-Hiroshima 2014 - ECCE ASIA). 2014. doi: 10.1109/ipec.2014.6869715

4. Integrated optimal design of a hybrid locomotive with multiobjective genetic algorithms / Akli C., Sareni B., Roboam X., Jeunesse A. // International Journal of Applied Electromagnetics and Mechanics. 2009. P. 151-162.

5. Hou R., Yang Y., Emadi A. Hybrid electric locomotive powertrains // 2014 IEEE Conference and Expo Transportation Electrification Asia-Pacific (ITEC Asia-Pacific). 2014. doi: 10.1109/itec-ap.2014.6940843

6. Kurz H. Rolling across Europe's vanishing frontiers [electric railway technology] // IEEE Spectrum. 1999. Vol. 36, Issue 2. P. 44-49. doi: $10.1109 / 6.744875$

7. Imitacionnaya model' tyagovogo ventil'no-induktornogo elektroprivoda / Ryabov E. S., Lyubarskiy B. G., Over'yanova L. V., Emel'yanov V. L. // Elektrotekhnika i elektromekhanika. 2009. P. 67-72.

8. Finite element modeling and control of a high-power SRM for hybrid electric vehicle / Sezen S., Karakas E., Yilmaz K., Ayaz M. // Simulation Modelling Practice and Theory. 2016. Vol. 62. P. 49-67. doi: 10.1016/j.simpat.2016.01.006

9. Kalaivani L., Subburaj P., Willjuice Iruthayarajan M. Speed control of switched reluctance motor with torque ripple reduction using non-dominated sorting genetic algorithm (NSGA-II) // International Journal of Electrical Power \& Energy Systems. 2013. Vol. 53. P. 69-77. doi: 10.1016/j.ijepes.2013.04.005

10. Xin Z., Yi T. Research of hybrid electric locomotive control strategy // 2011 International Conference on System science, Engineering design and Manufacturing informatization. 2011. doi: 10.1109/icssem.2011.6081159

11. Obgruntuvannia neobkhidnostinosti modernizatsii teplovozu ChME3 iz vykorystanniam hibrydnoi sylovoi ustanovky / Buriakovskyi S. H., Maslii A. S., Pomazan D. P., Denis I. V. // Elektryfiatsiya transportu. 2016. Issue 12. P. 82-86.

12. Krishnan R. Switched reluctance motor drives. Modeling. Simulation, Analysis, Design and Applications. CRC Press, 2006. P. 324-328.

13. Miller T. J. E. Optimal design of switched reluctance motors // IEEE Transactions on Industrial Electronics. 2002. Vol. 49 , Issue 1. P. 15-27. doi: 10.1109/41.982244

14. Rymsha V. V. Modelirovanie i sintez reaktivnyh i induktornyh elektromekhanicheskih preobrazovateley: dis.... d-ra tekhn. nauk / Odesskiy nacional'niy politekhnicheskiy un-t. Odessa, 2004. 336 p.

15. Firago B. I., Pavlyachik L. B. Teoriya elektroprivoda: ucheb. pos. 2-e izd. Minsk: Tekhnoperspektiva, 2007. 585 p.

16. Kochneva T. N., Kozhevnikov A. V., Kochnev N. V. Sintez modal'nogo regulyatora i ocenka effektivnosti modal'nogo upravleniya dlya dvuhmassovyh elektromekhanicheskih sistem // Vestnik Cherepoveckogo gosudarstvennogo universiteta. 2013. Issue 4 (52). P. $15-22$

17. Vadutov O. S. Nastroyka tipovyh regulyatorov po metodu Ciglera-Nikol'sa. Tomsk: TPU, 2013. P. 10-15.

18. Razrabotka i issledovanie sistemy upravleniya ventil'no-reaktivnym elektrodvigatelem / Buryakovskiy S. G., Lyubarskiy B. G., Masliy A. S., Masliy A. S. // Vestnik NTU «KhPI». Ser.: Problemy avtomatizirovannogo elektroprivoda. 2013. Issue 36. P. 195-197.

19. Analysis of optimal operating modes of the induction traction drives for establishing a control algorithm over a semiconductor transducer / Liubarskyi B., Petrenko A., Shaida V., Maslii A. // Eastern-European Journal of Enterprise Technologies. 2017. Vol. 4, Issue 8 (88). P. 65-72. doi: 10.15587/1729-4061.2017.109179

20. Optimization of thermal modes and cooling systems of the induction traction engines of trams / Liubarskyi B., Petrenko O., Iakunin D., Dubinina O. // Eastern-European Journal of Enterprise Technologies. 2017. Vol. 3, Issue 9. P. 59-67. doi: 10.15587/17294061.2017.102236 